ANuARIo DE Estudios MEdiEvales (AEM)

36/1, enero-junio de 2006

pp. $145-169$

ISSN 0066-5061

\title{
PESCA Y TRABAJO EN EL REINO DE TOLEDO. LA CUENCA ALTA Y MEDIA DEL TAJO EN LOS SIGLOS XII AL XVI
}

\author{
JULIÁN SÁNCHEZ QUIÑONES \\ Universidad Autónoma de Madrid
}

Resumen: Este trabajo trata acerca de las profesiones relacionadas con la pesca en el Reino de Toledo, en la cuenca alta y media del río Tajo, de los siglos XII al XVI. A lo largo de estas páginas hemos visto muchos tipos diferentes de personas, oficiales públicos, grandes mercaderes, trabajadores de las pesquerías, envueltos en la captura, comercio y distribución del pescado. Con este artículo, queremos romper con la idea que identifica la pesca sólo con los pescadores y los barcos, mostrando como la sociedad medieval se interesaba en cualquier actividad económica que produjese beneficios

Palabras clave: Reino de Toledo, Tajo, pesca, oficios, pescador, comercio, vendedores.

\begin{abstract}
This work treats about the professions related with the fishing in the Kingdom of Toledo, in the high and middle course of river Tagus, from XII-XVI ${ }^{\text {th }}$ centuries. Along these pages we have seen many different kind of people, public servants, great merchants, workers of the fisheries, involved in the fishing, trading and delivering of fish in this time. So with this article, we break with the idea which identified the fishing only with fishing men and boats showing how the medieval society was interested in every economic activity which produced profits.
\end{abstract}

Keywords: Kingdom of Toleto, Tagus, fishing, professions, fisherman, trade, sellers.

1. Los pescadores: 1.1 Los pescadores: procedencia y "status" social. 1.2 Los pescadores ilegales. 2. Propietarios y arrendatarios de las explotaciones pesqueras: 2.1 Los arrendatarios. 2.2 Los aparceros. 3. La custodia de los productos pesqueros: Los guardas. 4. Los comerciantes del pescado: 4.1 Los obligados. 4.2 Los cortadores. 4.3 Los corredores. 4.4 Los vendedores al margen del sistema 4.5 Los regatones. 4.6 Los vendedores ilegales 5. Conclusiones. 


\section{INTRODUCCIÓN}

El presente artículo con el que nos presentamos, formó parte de nuestro trabajo de investigación dedicado a la pesca en el Reino de Toledo, la cuenca alta y media del Tajo entre los siglos XII al XVI ${ }^{1}$. Con él, venimos a abordar una de las cuestiones menos trabajadas por el mundo del medievalismo, como es la pesca fluvial y su relación con los diversos oficios presentes en esta región en el período mencionado ${ }^{2}$. Es decir, lo que pretendemos a través de nuestro estudio, es efectuar una primera aproximación a los aspectos más relevantes de los individuos, que por su trabajo se veían ligados a una actividad singular en la tierra que habitaban. Al mismo tiempo pretendemos analizar su posición en la sociedad, su forma de actuación y su nivel de renta siempre en lo que atañe al mundo de la pesca, para conformar un amplio retrato de una realidad tan poco conocida. Desde luego su relación no era la misma en todos lo casos, por lo que hemos optado por dividirlos en cuatro grandes grupos: los que practicaban la pesca, los poseedores o arrendatarios de las grandes explotaciones pesqueras, los encargados de custodiar los productos pesqueros y los individuos que comerciaban con ellos.

Las fuentes empleadas para este propósito son los fueros y ordenanzas municipales publicadas, empleadas en este artículo por ser de fácil acceso, muy manejables y útiles para una aproximación inicial a esta cuestión, ya que son las que contienen una mayor cantidad de datos, por lo que permiten un análisis más preciso y profundo de los grupos sociales implicados.

${ }^{1}$ Dicho trabajo fue presentado y expuesto en la Universidad Autónoma de Madrid en junio de 2004 y mereció la máxima calificación de Sobresaliente $(10)$, por parte del tribunal que lo evaluó. Y se incluye dentro de un Proyecto de Investigación, financiado por la Comunidad de Madrid, bajo el titulo "Poder y organización territorial en el primitivo reino de Toledo" (Ref. 06/HSE/0009/2004).

${ }^{2}$ Las aportaciones a la investigación de la relación entre la pesca y el trabajo son muy escasas. Podemos mencionar aquí algunas obras: $\mathrm{M}^{\mathrm{a}}$ Soledad TENA GARCíA, Composición social y articulación interna de las cofradías de pescadores y mareantes (Un análisis de la explotación de los recursos marítimos en la marina de Castilla durante la Baja Edad Media) en "Espacio, Tiempo y Forma. Historia Medieval", 8, (1995), pp. $111-135$, que estudia las cofradías pesqueras del País Vasco; José Carlos VizUETE MENDOZA, Mudéjares toledanos y el monasterio de San Clemente en "IV Simposio Internacional de Mudejarismo. Economía", Teruel, 1987, pp. 65-73, que analiza el papel de los mudéjares toledanos en el arrendamiento de aparatos hidráulicos y por último la obra de Elisa FERREIRA PRIEGUE, Galicia en el comercio marítimo medieval, La Coruña, 1988, que trabaja sobre los pescadores, mareantes, comerciantes, siendo de lo más completo que se ha hecho hasta el momento. 
No obstante para determinados colectivos (aparceros, guardas) también hemos empleado documentación de tipo señorial, que enriquece la de tipo local y posibilita una visión más amplia sobre estos individuos.

\section{LOS PESCADORES}

A semejanza de las zonas costeras, el interior de la Península, y más concretamente nuestra zona, disponían de individuos, denominados pescadores por las fuentes, que se encargaban de capturar con los más diversos aparejos los frutos de los ríos. Hay que diferenciar, nosotros lo hemos hecho así, a los pescadores, que según todos los indicios podían tener ciertos rasgos de profesionalidad, de ciertas alusiones a personas que ocasionalmente y con medios prohibidos pescan en las aguas del territorio. Estos últimos personajes son realmente complicados de definir. Las menciones a ellos son muy parcas, ambiguas, lo que en muchos casos no permite aclarar su posición social, su nta $u$ otras cuestiones de interés. Los datos existentes son excesivamente fragmentarios y es muy difícil evaluarlos de manera exhaustiva, si bien a veces se desprende algún apunte interesante que sirve a nuestros propósitos. Para facilitar, de todos modos su comprensión, los hemos distinguido en dos apartados: pescadores y pescadores ilegales.

\subsection{Los pescadores: procedencia y "status" social}

En los fueros y ordenanzas municipales los términos pescadores, pescador o cualquiera derivado de esta familia son muy frecuentes y servían para referirse a estos personajes como gentes dedicadas a la pesca como profesión. No obstante, en la mayoría de los casos la información proporcionada no va más allá de reflejar el tipo de aparejos con que se había de pescar en las aguas del señorío o del concejo ${ }^{3}$. Por otro lado, tampoco refieren datos concernientes a su status social y a la procedencia de este grupo, o si se hallaban organizados en asociaciones colectivas. Queda claro eso sí que quedaban sujetos a las mismas leyes que regulaban todo el negocio de la pesca.

${ }^{3}$ Sirvan como ejemplo las disposiciones del Fuero de Madrid. Vid. Galo SÁNCHEZ, Fuero de Madrid, Madrid, 1994, p. 42. 
La primera pregunta que cabría plantearse es si este oficio, el de pescador, suponía para el que lo ejercía una única ocupación o si podía ser compaginada con otras. A este respecto, la legislación consultada muestra una cierta unanimidad, ya que todo apunta a que estos individuos podían tener un segundo trabajo que complementase al anterior.

No obstante, algunos autores como Julio González han apuntado la posibilidad de la existencia de pescadores a tiempo parcial y completo lo que dificulta aún más la resolución de este problema ${ }^{4}$.

En Toledo las ordenanzas de la villa recogen que podían ser propietarios o arrendadores de una posada a orillas del Tajo ${ }^{5}$. Lo que nos indica que poseían otra profesión. Pero incluso los oficios se podían ver relacionados puesto que las mismas leyes del concejo nos informan que empleaban su negocio para sacar fuera de la villa o del término municipal el pescado capturado en el río ${ }^{6}$.

Esto nos causa múltiples problemas a la hora de evaluar la rentabilidad de esta actividad: por un lado el individuo que se dedicaba a la pesca necesitaba disponer de una segunda ocupación para poder garantizar su supervivencia; por el otro se podría interpretar que merced a sus ingresos podía permitirse arrendar o incluso adquirir un negocio.

La posibilidad de una fuente de beneficios alternativa no es exclusiva de Toledo. En Madrid también se empleaban en otros trabajos aunque aquí se hallan relacionados con el mundo agrícola. En 1481 el municipio concedió a Juan de Valdivieso una tierra a censo perpetuo, la cual había pertenecido a su suegro García, cuya profesión era la de pescador. Asimismo se relata como este hombre, García, había tenido la heredad a censo del concejo y en ella había plantado una viña, descepada tras su muerte ${ }^{7}$. Muy mal no debían irle las cosas a este personaje para poder arrendar una tierra a la villa. En cualquier caso el alquiler impuesto a su yerno no era excesivo, tan sólo veinte maravedíes al año. Desconocemos la suma que le impusieron los regidores por el arrendamiento, pero no debía ser muy diferente. Por muy humilde que

${ }^{4}$ Julio GonZÁlez, Repoblación de Castilla La Nueva, vol. II, Madrid, 1975, p. 356.

${ }^{5}$ Ricardo IZQUIERDO BENITO, Abastecimiento y alimentación en Toledo en el siglo XV, Cuenca, 2002, p. 171.

${ }^{6}$ IZQUIERDO, Abastecimiento y alimentación en Toledo, p. 171.

${ }^{7}$ Agustín Millares Carlo; José Artiles Rodríguez, Libros de Acuerdos del Concejo Madrileño, vol. I, Madrid, 1932, p. 97. 
fuera es de prever que sus rentas fueran superiores, de lo contrario nunca hubiera podido acceder a semejante posesión.

Otro de los asuntos que podrían ayudar a describir la situación social de los pescadores es la posterior comercialización de los productos en el mercado. Ésta se reveló ciertamente difícil por el control que el concejo procuraba imponer al comercio dentro de sus muros. Como veremos más adelante, las autoridades municipales buscaron siempre disponer del abastecimiento adecuado para la alimentación de las villas y aldeas de la región. Dicho objetivo debía obedecer a dos requisitos básicamente: que los productos fuesen buenos y baratos, ofertándose de ese modo a los habitantes de los núcleos poblados al mejor precio posible, de ahí que se buscase gente capaz de proveer las mercancías según las intenciones del concejo. En ocasiones eran los propios alcaldes quienes escogían a unos individuos llamados corredores ${ }^{8}$, cuyas características explicaremos más adelante. Sin embargo ya a finales de la Edad Media, se arrendará la venta de estos productos y también del pescado a unos individuos llamados obligados ${ }^{9}$, a los que también prestaremos atención en este trabajo. Tanto los corredores como los obligados serán los únicos autorizados a vender el pescado en las respectivas villas, debiéndoseles entregar lo capturado y castigando con fuertes penas los intentos de venta ajenos a estos sistemas ${ }^{10}$. Las excepciones en que se permitían estas transacciones comerciales serán casos de auténtica necesidad y se reducen a ocasiones en que estos responsables no podían abastecer a los pobladores por carecer del producto requerido ${ }^{11}$.

Con todo ahí no acababan las dificultades para los pescadores. Sus ingresos quedaban sujetos además a las cargas fiscales que podían reducirlos de manera sustanciosa: así en la red del pescado de Toledo existían gravámenes adecuados a cada especie introducida, ya fuera esta de río o de mar,

\footnotetext{
${ }^{8}$ Así ocurría en Huete. Vid. $\mathrm{M}^{\mathrm{a}}$ Teresa Martín Palma, Los fueros de Villaescusa de Haro y Huete, Málaga, 1984, pp. 289-291.

${ }^{9}$ Para más información sobre este grupo véase el magnífico trabajo efectuado por Puñal Fernández para los obligados de Madrid. Vid. Tomás PUÑAL FERNÁNDEZ, El mercado de Madrid durante la Baja Edad Media, Madrid, 1992.

${ }^{10} \mathrm{El}$ fuero de Guadalajara prohibía a los pescadores vender en sus casas. Vid. Hayward Keniston, Fuero de Guadalajara, Nueva York, 1965, p. 4.

${ }^{11}$ José Miguel LóPEZ VILlalba, Las Actas de Sesiones del Concejo Medieval de Guadalajara, Madrid, 1997, pp. 140-141.
} 
yendo la cantidad de uno a diez maravedíes por carga ${ }^{12}$. El libre comercio era por ello casi imposible viéndose por un lado estrechados por los sistemas comerciales imperantes y por el otro por las abusivas tasas impositivas.

No obstante y como ya comentábamos anteriormente, había momentos en los que su concurso se hacía indispensable. En Madrid, por ejemplo, los Libros de Acuerdos del Concejo recogen la existencia de unos personajes denominados pescadores, que al parecer eran los encargados de una tabla de pescado. Sus apariciones son contadas, pero muy interesantes. Por ejemplo en 1496 el concejo acordó no disponer de obligados y estipuló permitir la libre venta de pescado çeçial a estos individuos con tal del que lo vendieran a ocho maravedíes la libra y debiendo asumir además la responsabilidad del abastecimiento el resto del año ${ }^{13}$. Como podemos observar las condiciones impuestos por los regidores madrileños son muy similares que las correspondientes a los obligados, teniendo el compromiso de abastecer de manera regular a la villa y a un buen precio. No podemos precisar sin embargo, si estos pescadores, a los que alude el texto, eran simplemente unos vendedores o si por el contrario ejercían además con la red y la caña, lo que vendría a confirmar la hipótesis que planteamos anteriormente y que decía que los pescadores ejercían diferentes oficios, en muchos casos además relacionados con su actividad pesquera.

Su presencia por otro lado no era privativa de la villa madrileña. En otros lugares como Maqueda ${ }^{14} \mathrm{o} \mathrm{Hita}{ }^{15}$, o incluso Córdoba ${ }^{16}$ quedan reflejadas las actividades de estos personajes, si bien en estos casos se habla de pescaderas o sardineras. Curiosamente, parecen no hallarse ligadas al régimen de obligados, sino que si se analiza cada población independientemente de las otras se observa que en Maqueda, van englobadas dentro de un

${ }^{12}$ Exceptuadas del arancel quedaban ciertas especies pescadas con caña, las llamadas costeras, posiblemente de río. Vid. Emilio SÁEZ, Aranceles de Toledo de 1562 en "Anuario de Historia del Derecho Español (AHDE)", 13-14 (1943), pp. 546 -560.

${ }^{13}$ Carmen Rubio Pardos; Trinidad Moreno ValCáRCel; Concepción de La Fuente COBOS; Emilio MENESES GARCÍA, Libros de Acuerdos del Concejo Madrileño (1493-1497), vol. III, Madrid, 1979, p. 233. p. 623 .

${ }^{14}$ Vid. Antonio Malalana Ureña, Las Ordenanzas de Maqueda en “AHDE”, 57 (1987),

${ }^{15}$ Luis Miguel de LA CruZ Herranz, La vida local en las Ordenanzas municipales: Hita (siglos XV-XVI) en "EEM", 21 (1998), p. 386.

${ }^{16}$ Pilar HeRNÁNDEZ IÑIGO, La pesca fluvial y el consumo de pescado en Córdoba (1450$1525)$ en "Anuario de Estudios Medievales (AEM)", 27 (1997), pp. 1089-1090. 
título dedicado a los regatones, en Córdoba son asalariadas de los merchantes o comerciantes que traían pescado de fuera y en Hita parece que van por libre, siendo la venta en los tres casos su medio de vida. También se habla de pescaderas en Toledo, ocupadas en las tiendas viejas a espaldas de la catedral. Como en los casos precedentes no podemos aclarar si iban o no ligadas al sistema de obligados ${ }^{17}$. La excepción podría ser Madrid, donde los obligados son llamados en ocasiones pescaderos o pescadores, pero la naturaleza de la documentación estudiada descarta esta posibilidad, por cuanto queda bien claro que se está refiriendo a gente aparte de los encargados del abastecimiento.

Una última vía era la venta a los regatones. Desconocemos si las altas tasas que estos individuos imponían a sus precios en la reventa se aplicarían también a la hora de pagar a sus proveedores. Probablemente el beneficio para los pescadores fuera mayor. De lo contrario nadie se arriesgaría a ser castigado por las leyes municipales.

\section{2. Los pescadores ilegales}

Como ya anticipamos en páginas precedentes, las fuentes no son ni excesivamente prolijas ni muy claras al tratar este tema. Normalmente, la ambigüedad suele ser lo más corriente cuando se refieren a estos pescadores que nosotros hemos denominado ilegales. En cierto modo esta ha sido una de las razones para separarlos de los pescadores de profesión que veíamos en el apartado anterior. Nos parecía muy arriesgado situar a ambos grupos en un mismo epígrafe, cuando creemos que hay razones fundadas, a pesar de la imprecisión de las fuentes, para poder considerar a estos últimos como un grupo aparte.

En cualquier caso, lo habitual es que los fueros y ordenanzas nos remitan a ellos en términos excesivamente generalistas. La forma de referirse a ellos es como: "(..) qualquier persona $(\ldots)^{118}, "(\ldots)$ todo aquel $(\ldots)^{119}$, siendo la inexactitud el rasgo predominante.

\footnotetext{
${ }^{17}$ IZQUIERDO, Abastecimiento y alimentación, pp. 170-171.

${ }^{18}$ Timoteo Domingo Palacios, Documentos del Archivo de Madrid, vol. III, Madrid, 1907, pp. 537-538.

${ }^{19}$ Rafael de Ureña Smenjaud, Fuero de Zorita de los Canes, Madrid, 1911, Título 745.
} 
Algunos documentos suelen ser más explícitos y hacen alusión a grupos sociales más concretos, como es el caso de Hita que al hacerlo se refiere a "(..) forasteros y (...) naturales de la dicha mi villa de Hita y su tierra y Trixueque (...)"20. Sin embargo la razón fundamental para hacer la separación de la que hablábamos, es la aparición de diversas referencias en los municipios de la zona, que documentan numerosas infracciones que atentaban contra la pesca por parte de colectivos ajenos a los pescadores. En Madrid sin ir más lejos, son los propios arrendadores de los ríos quienes osaban envenenar las aguas ${ }^{21}$. Una tendencia que es confirmada por las ordenanzas de Toledo que afirmaban lo siguiente: "(...) hemos visto el desorden que (...) se ha tenido en el pescar en este rio de Tajo (...) a cuya causa hay muy poco pescado en el dicho río (...) por la qual mandamos, que de aquí adelante ninguna ni algunas personas, de ningún estado que sean $(\ldots)^{122}$ y la cita continúa estableciendo los métodos prohibidos y las penas por usarlos.

Esto podría ratifica, hasta cierto punto, una tendencia del común de la población a pescar de manera ilegal cualquiera que fuera su posición y status. Recordemos de nuevo a los arrendadores del río de Madrid o incluso a los de Toledo $^{23}$, que promovían una pesca ilegítima en sus heredades arrendadas, tal y como recogen las leyes de la ciudad. Gente sin duda alguna con una capacidad adquisitiva superior a la del resto de la población. Las ordenanzas toledanas sugieren aún indirectamente que semejantes prácticas no son desconocidas por los sectores más pudientes, como pudimos ver en la cita anterior.

Como conclusión a este epígrafe hay que referir que los pescadores no eran tampoco ajenos a estos modos de captura. Los fueros les prohibían determinados sistemas de pesca $^{24}$, perjudiciales para las especies piscícolas, lo que reforzaría la idea de una implicación de la sociedad en una pesca ilegal.

${ }^{20}$ LA CRUZ, La vida local en las Ordenanzas municipales en "EEM”, 21 (1998), p. 399.

${ }^{21}$ Agustín GómeZ IGLESIAS, Libros de Acuerdos del Concejo Madrileño (1486-1492), vol. II, Madrid, 1970, pp. 161-164.

${ }^{22}$ Martín Gamero, Ordenanzas antiguas de Toledo, Toledo, 1858, pp. 166-167.

${ }^{23}$ IZQUIERDO, Abastecimiento y alimentación, p. 212.

${ }^{24}$ Quedaban prohibidas las presas y canales en determinados sectores de los ríos o en su totalidad. Vid. SÁNCHEZ, Fuero de Madrid, p. 42. 


\section{PROPIETARIOS Y ARRENDATARIOS DE LAS EXPLOTACIONES PESQUERAS}

En la segunda parte de este artículo vamos a afrontar el análisis de los grupos sociales que se hicieron cargo del usufructo de las grandes explotaciones pesqueras. Entendemos que un paso previo a meternos de lleno a explicar esta cuestión debe ser una breve introducción al mundo de los aparatos hidráulicos y su modo de aprovechamiento. Era norma común que los arrendadores o los aparceros de estos instrumentos no quedasen limitados tan sólo al aparato en sí, sino que su contrato abarcaba un territorio, en este caso una parte de la orilla del río junto al cual se situaba el objeto de arrendamiento. La legislación municipal suele ser muy clara a este respecto y cada propietario y, a través de él el arrendador, disponía de un trozo de orilla y agua para ejercer su actividad. Las Ordenanzas de Alcalá de 1509 quizás sean el exponente más preciso, determinando que el dueño de un molino podía echar una piedra con su mano hacia arriba y lo que alcanzare ésta, se convertía en un espacio acotado para la pesca. Sin embargo del cóncavo ayuso podría hacerlo quien quisiere ${ }^{25}$.

Los arrendadores recibían estos bienes de los propietarios, a través de un contrato, con el que adquirían una serie de compromisos, relativos al mantenimiento y cuidado de las instalaciones, que analizaremos más adelante. El origen social de los propietarios era muy diverso afectando a la monarquía, Órdenes Militares, señores laicos, pequeños particulares o a los poderes episcopales de la zona $^{26}$. Asimismo algunos autores han destacado la importancia que este tipo de posesiones tenían para las Órdenes Militares del lugar ${ }^{27}$. Respecto a la tipología de los instrumentos alquilados, donde la variedad era la nota predominante. Aquí hallamos molinos, canales, presas, algunos de los cuales aún hoy están muy poco estudiados, y a los que nos iremos refiriendo poco a poco.

${ }^{25} \mathrm{M}^{\mathrm{a}}$ Dolores CABAÑas GONZÁLEZ, Hordenanças et fuero de la Villa de Alcalá de Henares, Alcalá de Henares, 1999, p. 2.

${ }^{26}$ Por ejemplo el cabildo de la catedral de Toledo disponía de aceñas y canales en su patrimonio rural. Ricardo IZQUIERDO BENITO, Patrimonio del cabildo de la catedral de Toledo, Toledo, 1980, p. 106.

${ }^{27}$ Como ejemplo valgan los trabajos de Enrique RoDRíGUEZ-PICAVEA, La formación del feudalismo en la meseta meridional castellana. Los señoríos en la Orden de Calatrava en los siglos XII-XIII, Madrid, 1994 y de María Milagros RIVERA GARRETAS, La encomienda, el priorato y la villa de Uclés en la Edad Media (1174-1310), Madrid-Barcelona, 1985. 


\subsection{Los arrendatarios}

En la introducción a este epígrafe ya fuimos viendo algunas de las claves que definían a este grupo y a los dueños de los aparatos que arrendaban. Habíamos explicado todo lo relacionado con la propiedad y el paso siguiente sería efectuar una primera aproximación respecto a su procedencia social.

Concretarlo es muy complejo pues las fuentes consultadas no se muestran claras, sino que como ocurría en el caso de los pescadores ofrecen datos puntuales sobre los respectivos arrendamientos y sus características, sin que en muchos casos profundicen más en la cuestión. Así ocurre en la ciudad de Guadalajara donde las tablas del río pertenecientes al concejo eran alquiladas en beneficio de otras personas o instituciones, posiblemente a cambio de un pago, del que no tenemos datos ni para el que se estipulan $\operatorname{cifras}^{28}$. Más valiosas son las indicaciones que se nos ofrecen para Madrid. En esta villa los arrendatarios se comprometían, según se dice en el documento, a una serie de obligaciones como construir un número determinado de judrias, las que el concejo estimase oportuno ${ }^{29}$.

¿Pero que era una judria? Para una mayor claridad en nuestra exposición, vamos a hacer un pequeño paréntesis y explicar en que consistía este aparato hidráulico. En lo referente a ella, aún hoy son muchos los interrogantes que la rodean. Para algunos autores como Rodríguez-Picavea era un instrumento similar a la pesquería ${ }^{30}$. La pesquería, a su vez era una especie de presa situada en los cauces de los ríos, construida de madera, cuya misión era abastecer de agua a los molinos y a su vez servía para pescar. Los datos que poseemos para la judria parecen confirmar una cierta similitud con la pesquería. Por un lado en 1481 varios vecinos de Vicálvaro solicitaron al concejo de Madrid una costa para hacer una judria ciega y pescadera ${ }^{31}$. Por

${ }^{28}$ Francisco Layna Serrano, Historia de Guadalajara y sus Mendozas en los siglos $X V-X V I$, vol. II, Guadalajara, 1994, p. 505.

${ }^{29}$ "Acordaron los dichos señores que Caçeres vaya a la Ribera e tome dos personas de Vicalvaro que sean Juan Martin e Bartolome Sanchez e vea la neçesidad donde son menester las xudrias que deuen los arrendadores de lo pasado para que se hagan y se traya la relaçion" Vid. Carmen RUBIO PARDOS; Rosario SÁNCHEZ GONZÁLEZ; Carmen CAYETANO MARTín, Libros de Acuerdos del Concejo Madrileño (1498-1501), vol. IV, Madrid, 1982, p. 295.

${ }^{30} \mathrm{Vid}$. RODRÍGUEZ-PICAVEA, La formación del feudalismo en la meseta meridional castellana, p. 220.

${ }^{31}$ Millares; ARTiles, Libros de Acuerdos, vol. I, p. 99. 
el otro en las Relaciones Topográficas de Felipe II, en el título de Arganda, se habla de unas pesquerías, que a su vez son doce judrias ${ }^{32}$, construidas también con madera. No podemos precisar por lo demás que sean lo mismo, pero todo apunta a que existían bastantes semejanzas entre ellas. No obstante otros autores como Losa Contreras identifican dicho instrumento como unos canales que servirían para evitar la crecida de los ríos ${ }^{33}$.

La hipótesis que planteamos es que para construir estas judrias, exigidas por el concejo, se requeriría un cierto esfuerzo financiero, que era pagado por los arrendatarios. Para afrontar lo que se les pedía, debían disponer de una cierta solvencia económica y ser capaces de hacer frente a su construcción o reparación, así como a cualquier contingencia que se pudiese presentar, ya que así se les exigía en el contrato. Volviendo a la judria que solicitaron construir los vecinos de Vicálvaro en 1481, estos recibieron juramento para saber a lo que eran obligados los arrendadores de los ejidos y carrascales de los años pasados ${ }^{34}$. Estamos por tanto ante unos arrendatarios que deben cumplir una serie de obligaciones, en este caso edificar una judria, para lo cual deben disponer de recursos económicos. Igualmente podríamos apuntar algo similar para Toledo, merced a los estudios que llevó a cabo Izquierdo Benito sobre las posesiones rurales y urbanas del cabildo toledano.

En las condiciones del contrato se establecía la obligación de mejorar el bien, en el caso que nos interesa los molinos y hacer reparaciones ${ }^{35}$, tareas que sólo podrían ser asumidas por alguien con la capacidad económica suficiente para ello. De todos modos no hay que dejarse engañar en este sentido. Estudios recientes han venido a demostrar como la función de molinero podía ser ejercida incluso por esclavos o minorías confesionales ${ }^{36} \mathrm{y}$ 1949 , p. 23 .

${ }^{32}$ Carmelo VIÑAS; Ramón PAZ, Relaciones Topográficas de Felipe II. Madrid, Madrid,

${ }^{33}$ Carmen LOSA CONTRERAS, El concejo de Madrid en el tránsito de la Edad Media a la Edad Moderna, Madrid, 1999, p. 399.

${ }^{34}$ Millares; Artiles, Libros de Acuerdos, vol. I, p. 99.

${ }^{35}$ IZQUIERDO, Patrimonio del cabildo, p. 152.

${ }^{36}$ Entre los mudéjares se dan los dos casos: hay esclavos molineros y mudéjares que son arrendatarios. Vid. VIZUETE, Mudéjares toledanos y el monasterio de San Clemente en "IV Simposio Internacional de Mudejarismo. Economía”, pp. 65 -73. 
si se trataba de una Orden Militar podían hacerlo miembros de ella o sus familiares ${ }^{37}$.

Cada situación era distinta. Podría llegarse al caso extremo de que hubiese que rehacer de nuevo el molino. Así ocurre con Mancilazeuden, cuando el cabildo lo dona a unos particulares para que hagan la azuda y la presa con sus bocas y canales ${ }^{38}$. Claro que aquí estamos hablando de una donación, pero las obligaciones que deben cumplir son las mismas que cualquier otro arrendatario: reedificar los bienes anteriormente dichos y pagar cada año un tributo al cabildo. Conocemos los nombres de los protagonistas pero no podemos saber a ciencia cierta su procedencia social.

\subsection{Los aparceros}

Sus condiciones de trabajo son muy similares a las comentadas para los arrendatarios. También ellos tenían una serie de compromisos con los dueños de los instrumentos. Así se ve por ejemplo en 1226, cuando el maestre de Santiago hizo un acuerdo de aparcería con Martín el abad, para que éste y sus compañeros hiciesen azudas en la aceña de Aranjuez. En el contrato se decía que él y sus aparceros debían encargarse de las obras, repartiéndose los beneficios a razón de dos tercios para ellos y un tercio para la Orden.

La procedencia de Martín confirma nuestras hipótesis del amplio radio de acción que podían tener estas formas de explotación. Más problemas nos plantea el término genérico de aparceros, de los que sólo se dice que: "(...) Martin, abbat, e sus aparçeros fagan siempre todas las lavores e den todas las despensas $(\ldots)^{139}$.

Lo más lógico sería pensar en la existencia de un vínculo entre Martín y el resto de los hombres, que parecen estar subordinados a él. Su misión en un principio se encaminaría a poner en funcionamiento lo que se les había encomendado. Parece del mismo modo que ellos podrían ser los encargados de explotarla, ya que se pone como condición que si no hubiese nadie que las

\footnotetext{
${ }^{37}$ Para los grupos o instituciones que podían hacerse cargo de ello. Vid. Pedro Andrés PoRRAS ARBOLEDAS, La Orden de Santiago en el siglo XV, Madrid, 1997, p. 178 y RODRÍGUEZ-PICAVEA, La formación del feudalismo en la meseta meridional castellana, pp. 229 y ss.

${ }^{38}$ Javier GARCía MARTín, Fueros eclesiásticos de Toledo: ¿Derecho territorial o derechos locales integrados en un régimen señorial? en Alvarado Planas, J, (dir) "Espacios y fueros en Castilla-La Mancha (Siglos XI -XV). Una perspectiva metodológica", Madrid, 1995, pp. 252253.

${ }^{39}$ RIVERA, La encomienda, el priorato y la villa de Uclés, pp. 264-265.
} 
labrase durante un año, el comendador debería escoger a una persona para hacerlo y ellos perderían la posesión ${ }^{40}$. La dificultad estriba por tanto en saber a quienes designaría el abad para realizar este cometido y las condiciones a las que tendría que someterse.

\section{LA CUSTODIA DE LOS PRODUCTOS PESQUEROS: LOS GUARDAS}

Una de las cuestiones más espinosas que afectó a la pesca fue su protección frente a los furtivos. Ya en páginas precedentes, dimos cuenta del comportamiento poco ejemplar de algunos sujetos que, saltándose cualquier tipo de ley o norma, optaban por ignorar la reglamentación existente con respecto a la pesca y ejercían dicha actividad de manera fraudulenta y en ocasiones muy dañina para el propio medio. Es por ello que los distintos poderes procuraron dotarse de una rudimentaria policía que vigilase sus propiedades y al mismo tiempo que actuase de forma eficaz y efectiva contra los peligros que acechaban.

El método según jurisdicciones y zonas fue curiosamente bastante parecido, recurriéndose a guardias que patrullaban los términos del señorío o del concejo municipal en busca y captura de los posibles malhechores.

En Madrid, por ejemplo, tenemos documentada la existencia de los guardas, a través de las ordenanzas de Policía Rural que indican su aparición en los sotos y ejidos de la villa ${ }^{41}$. No sabemos mucho de esta figura. Se llevaba las dos terceras partes de las multas impuestas a los pescadores ilegales, por lo que debía ser un puesto codiciado por el gran beneficio que conllevaba, pero nada se dice de su procedencia social ${ }^{42}$. También podemos localizarlos en las tierras señoriales de Buitrago. Aquí incluso se podría hablar de una jerarquía, ya que había un guarda mayor que era el encargado de hacer jurar el oficio a nuevos guardas y de que estos tuviesen en orden la cédula, que era el documento que les capacitaba para ejercer el $\operatorname{cargo}^{43}$.

\footnotetext{
${ }^{40}$ RIVERA, La encomienda, el priorato y la villa de Uclés, pp. 264-265.

${ }^{41}$ Domingo, Documentos del Archivo, vol. III, pp. 545 -546.

${ }^{42}$ Domingo, Documentos del Archivo, vol. III, pp. 545-546.

${ }^{43}$ Matías Fernández García, Fuentes para la Historia de Buitrago y su tierra, Madrid,
} 2001, p. 135. 
En Hita, perteneciente como Buitrago al señorío de los Duques del Infantado, la máxima autoridad era por el contrario el alcaide ${ }^{44}$, cuyas funciones nos son desconocidas. No sabemos asimismo si el guarda mayor es una creación del siglo XVI, fecha de las ordenanzas de Buitrago y por tanto antes existía otra figura o si por el contrario era un remanente de los siglos medievales.

En todo caso la misión de ambos era capturar a los furtivos y ponerlos en manos de la justicia, ya fuera el corregidor, caso de Hita, o el guarda mayor en Buitrago, dado que en esta última localidad también podía ejercer de juez. Una cuestión registrada en esta población es que los guardas debían jurar que no harían avenencia de cualquier tipo con los delincuentes ${ }^{45}$, lo que induce a creer en una cierta complicidad con los infractores a cambio de una parte del botín conseguido y por otro lado a cuestionarse su eficacia en el cumplimiento de las tareas encomendadas.

\section{LOS COMERCIANTES DEL PESCADO}

El comercio fue posiblemente el método más eficaz de sacarle partido a las capturas pesqueras, a través de su venta al consumidor. No obstante y como ya apuntamos cuando hablábamos de los pescadores, las transacciones mercantiles se hallaban sujetas a la rígida reglamentación concejil que procuraba garantizar un abastecimiento de buena calidad y a precios asequibles para el consumidor. Por ello se reguló esta actividad por medio de dos sistemas. El primero es el sistema de obligados, consistente en que el concejo arrendaba la venta del pescado a un particular, que se comprometía a traerlo y a venderlo según los precios marcados por el municipio ${ }^{46}$. Sin embargo en otras localidades, lo que hallamos es una persona nombrada específicamente por el concejo y que responde al nombre de corredor. A esta diferencia en su nombramiento se añade además que el obligado debía traer la mercancía a la población, desde donde fuese, mientras que el corredor se limitaba a vender los productos que le eran entregados ${ }^{47}$. Por lo demás era

\footnotetext{
${ }^{44}$ LA CRUZ, La vida local en las ordenanzas municipales en "EEM", 21 (1998), p. 399.

${ }^{45}$ FERNÁNDEZ, Fuentes para la Historia de Buitrago, p. 135.

${ }^{46}$ PuÑal, El Mercado de Madrid, 1992.

${ }^{47}$ UreÑA, Fuero de Zorita de los Canes, Título 369.
} 
como en el caso anterior el único que podía vender en el término municipal, debiendo acudir a él todo aquel que quisiese poner en el mercado cualquier producto.

Ambas figuras simbolizan por tanto el enorme interés de los concejos medievales por controlar cuanto se compraba y se vendía dentro de sus muros y constituirían lo que hemos venido a llamar la venta legal, los sistemas permitidos por los municipios.

Dicho control, sin embargo, se veía comprometido en multitud de ocasiones. La actuación de los regatones, constituyó un constante desafío al comercio barato y fácil que querían los regidores municipales. Con sus actuaciones poco claras y que transgredían fundamentalmente los precios marcados por el concejo, pasaron a ser un continuo estorbo que impedía el control absoluto de las transacciones locales. Tal es así que Tomás Puñal en su obra relativa al mercado en Madrid a finales de la Edad Media, señala que el incumplimiento de los precios por parte de los regatones era una razón para que el concejo les persiguiera ${ }^{48}$.

Con todo no fueron los únicos que contravenían las ordenanzas. Quedan documentados diversos individuos, difíciles de identificar, puesto que las fuentes nos son esquivas a la hora de dar información, que no eran regatones y cuyo modo de operar era casi idéntico al de estos. Tanto los regatones como estos individuos representaban a aquellos que vendían de forma ilícita en el municipio, lo que hemos denominado la venta ilegal.

A todo lo anterior habría que añadir otros dos grupos relacionados con el comercio. Uno de ellos íntimamente ligado a los obligados, posiblemente como asalariados de éstos: los cortadores. Las referencias halladasno son muchas pero todo apunta a que se trataba de los encargados de vender el pescado en las tablas o puestos establecidos para ello. El segundo colectivo se halla, como en el caso de los vendedores ilegales a los que nos referíamos anteriormente, en una situación de indefinición absoluta. Sabemos muy poco de ellos, ya que los documentos no aportan demasiados datos, pero son realmente importantes, puesto que constituyen el único caso en que los concejos hacen excepciones en la venta del pescado, permitiéndoles que abastezcan a la villa en un determinado momento, posiblemente de necesidad o de incapacidad del obligado de cumplir lo pactado.

${ }^{48}$ Vid. PUÑal, El Mercado de Madrid, p. 186. 


\subsection{Obligados}

Hora es de ocuparse de la dimensión social que la pesca adquirió en el comercio y de sus implicaciones respecto de los hombres que la ejercieron.

En este punto hemos querido referirnos a uno de los dos sistemas más importantes ligados a la actividad comercial: los obligados. Acerca de ellos se han empezado a hacer importantes investigaciones, aunque éstas se centran en todo lo que tiene que ver con el comercio, descuidando de ese modo el enfoque social de la cuestión.

En su obra relativa al mercado de Madrid, Puñal Fernández se limitaba a indicar que los obligados eran personas que se encargaban de abastecer de pescado a la ciudad sin entrar en más detalles en lo referente a su procedencia social. Igualmente apuntaba que algunas familias, valgan como ejemplo los Franco, ocupaban de manera reiterada el cargo. Este es un hecho cuando menos curioso, ya que efectivamente en los documentos consultados, no sólo los Franco sino que también otros personajes se repiten de manera insistente a lo largo del período ${ }^{49}$.

La causa de esta escasa variedad, podría residir en varios factores: bajos precios de los productos motivados por la política concejil de un abastecimiento de calidad y barato, las lógicas dificultades para traer la mercancía desde los puertos y un último factor que estaría directamente relacionado con la posición social de estos personajes: el cumplimiento del contrato firmado. Recordemos de nuevo cual era la principal misión del obligado: abastecer a la villa del pescado, ya fuera de río o de mar, lo que probablemente suponía transportarlo de puertos marítimos con el consiguiente costo, que iba con cargo a su bolsillo ${ }^{50}$. Además debía ponerse como fianza a sí mismo y a sus bienes y en caso de incumplimiento abonar las multas cuyas sumas podían ser muy cuantiosas ${ }^{51}$. Por no mencionar la más que probable remuneración que deberían abonar a aquellos que trabajaban para

${ }^{49}$ Alonso de Torres fue obligado en 1492, así como en 1493, 1494, 1495 y 1496. En 1491 dio pescado por un breve tiempo pero sin ejercer como obligado. Vid. GómEZ, Libros de Acuerdos, vol.II, pp. 259 y 338; RUBIO; MORENO; LA FUENTE; MENESES, Libros de Acuerdos, vol. III, pp. 28, 88, 160-161 y 239-240.

${ }^{50}$ Se mencionan para Guadalajara y Madrid los puertos de Sevilla, Palos, Portugal o Galicia. Vid. LóPEZ, Las Actas de Sesiones, pp. 298 -299 y 306 -307 y MillaRES; ARTILES, Libros de Acuerdos, vol. I, pp. $192-194$.

${ }^{51}$ En Guadalajara se llegan a fijar 100.000 maravedíes de multa. Vid. LÓPEZ, Las Actas de Sesiones, pp. $311-312$. 
ellos: los vendedores y cortadores de las tablas a los que, como veremos en el próximo epígrafe, les debía unir un vínculo de tipo contractual.

Un panorama similar hallamos en Guadalajara donde el número de obligados también es muy reducido. Esta circunstancia podría indicar, entre otras cosas, las dificultades para cumplir las exigencias del concejo. Como en Madrid, posiblemente se veían obligados a traer pescado de los puertos, ya fueran Sevilla, Palos o incluso Portugal y también debían responder con sus personas y sus bienes del cumplimiento del contrato.

A todas estas condiciones, se unían además otras tales como las de disponer de un determinado número de tablas en la villa, lo que sumado a los precios bajos del municipio debían motivar una escasez alarmante de voluntarios.

De hecho, no eran raros los casos en los que se comentaba que no se pudo conseguir un obligado para la villa, por lo que se convocaba el remate para el que quisiese hacerse cargo de la pescadería ${ }^{52}$. Llegando a darse el caso de que si el obligado no podía abastecer a la ciudad, el concejo hiciese la vista gorda con los pequeños vendedores ${ }^{53}$, lo que explicaría la necesidad de que fuese una persona con posibles para hacer frente a las obligaciones de su cargo.

\subsection{Los cortadores}

En la introducción ya habíamos mencionado como los cortadores estaban ligados a los obligados. De ello dan cuenta las fuentes, que de vez en cuando ofrecen unos ciertos trazos sobre este grupo poco conocido y estudiado.

Esta cuestión ya fue brevemente tratada por Tomás Puñal en su obra relativa al mercado de Madrid ${ }^{54}$. Dicho autor planteaba acertadamente en sus páginas la condición de vendedores del pescado de este grupo social. Semejante afirmación encuentra cabida en la documentación consultada que recoge, junto a otras, dicha actividad. Así, en 1498 el concejo estipulaba que los cortadores no diesen pescado de las tablas de los caballeros y escuderos

${ }^{52}$ Rubio; Moreno; La Fuente; Meneses, Libros de Acuerdos, vol. III, p. 233.

${ }^{53}$ LÓPEZ, Las Actas de Sesiones, pp. 140-141.

${ }^{54}$ PUÑAl, El Mercado de Madrid, 1992. 
a los pecheros, teniendo que conformarse éstos con las mercancías disponibles en las suyas ${ }^{55}$.

No obstante, a esta actividad hemos de añadir por otro lado la que su nombre indica, la de cortadores, es decir, parece, a tenor de lo que se menciona en los textos, que su segunda función era la de cortar el pescado para su posterior consumo. Tal es así que en 1494 los regidores ordenaron que el cortador que cortase carne o pescado podrido fuese llevado a la vergüenza pública por toda la villa ${ }^{56}$. No queda claro de todos modos, si exclusivamente se encargaban de trocearlo o si efectuaban una preparación más exhaustiva del producto, lo que no sería raro teniendo en cuenta que eran los encargados de su perfecta conservación hasta el momento de su venta.

La elección para ejercer en dicho puesto corría a cargo de los propios obligados, los cuales les pagarían por ejercer esta labor.

Por ejemplo se puede citar a un tal Abraén Çidré, que en 1482 fue señalado por Juan de Toledo, obligado de la villa, como única persona en la que podía confiar para vender el pescado ${ }^{57}$. Su nombre señala una más que probable procedencia judía y por añadidura el documento nos lo señala como el encargado de vender la mercancía, si bien no como cortador.

No es el único, ya que además el escribano recoge las lamentaciones del obligado, el cual dice que este Abraén es una persona de fiar, un modelo de conducta frente al resto y que no puede fiarse de nadie más para despachar el pescado, lo que significa que había otros.

Los problemas con este grupo social no son nuevos. Si recordamos las referencias anteriores, vemos que los cortadores son mencionados en razón de asuntos poco claros, como productos en mal estado o la venta a pecheros en tablas que no les corresponden. Para la situación de Juan de Toledo desconocemos a que se debe su queja, pero probablemente sería por algún motivo similar. El objetivo de tales acciones estaría encaminado, a conseguir una mayor suma por parte de los pecheros y que presumiblemente se embolsarían ellos mismos, o si del pescado en mal estado se trata, de evitar las pérdidas derivadas de sacar la parte afectada fuera de la circulación.

${ }^{55}$ Rubio; SÁnChez; CAYETANo, Libros de Acuerdos, vol. IV, pp. 59-60.

${ }^{56}$ Rubio; Moreno; LA Fuente; Meneses, Libros de Acuerdos, vol. III, p. 89.

${ }^{57}$ Millares; ARTiles, Libros de Acuerdos, vol. I, pp. 192-194. 


\subsection{Los corredores}

Muy distinta al sistema de obligados era la figura del corredor. Nuestra información a este respecto proviene íntegramente de los fueros y lo que apuntan éstos es una forma de elección y actuación radicalmente diferente a la que se vio para el obligado. De entrada su función era más de intermediario que la de un proveedor de mercancías. El corredor recibía toda clase de productos y los vendía, quedándose en beneficio con una parte de lo obtenido $^{58}$.

Su elección se debía a una decisión de los alcaldes, si bien desconocemos los requisitos que debía reunir el candidato para ser escogido ${ }^{59}$. Lo cierto es que las rentas derivadas de su puesto no debían ser desdeñables y si bien cuando iniciaba el oficio su patrimonio podía ser reducido, probablemente y gracias al ejercicio de su cargo éste se vio notablemente incrementado.

\subsection{Los vendedores al margen del sistema}

Fuera del sistema, si bien dentro de la legalidad, quedarían diversas transacciones efectuadas de manera ajena a los obligados y corredores.

Se trataba por lo general de intercambios comerciales efectuados con el consentimiento del concejo, que permitía a una serie de personajes, sin especificar, vender determinados productos de origen marítimo o fluvial.

Así en 1489 en la villa de Madrid, "(...) ordenaron que qualquier vezino desta Villa pueda vender una libra de peçes en un dia donde quisiere sin pagar derecho alguno, con tanto que en aquel dia no venda mas (..." ${ }^{\prime 60}$. Esta disposición, ambigua, podría estar refiriéndose tanto a pescado de río como de mar.

En Guadalajara las autoridades dieron permiso para vender sardinas fuera del control del obligado ${ }^{61}$. En 1482 en Madrid se repitió una disposición parecida, donde determinados individuos podían vender pescado y sardina sin

\footnotetext{
${ }^{58}$ Ureña, Fuero de Zorita de los Canes, Título 369.

${ }^{59}$ Martín Palma, Los fueros de Villaescusa de Haro y Huete, pp. 289-291.

${ }^{60}$ GómEZ, Libros de Acuerdos, vol. II, pp. 161-164.

${ }^{61}$ LóPEZ, Las Actas de Sesiones, pp. 140-141.
} 
incurrir en pena alguna ${ }^{62}$. No tenemos ninguna explicación a este fenómeno, siendo muchas nuestras dudas acerca de la procedencia de estos hombres.

Un breve vistazo a las listas de precios que hemos manejado hasta el momento, nos indica que por ejemplo, la sardina era un pescado barato tasado a seis maravedíes y medio. Casi cualquiera que lo desease podía comprar una partida de este producto y venderla posteriormente, con lo que podríamos apuntar a un origen ciertamente humilde de estos vendedores. Sin embargo, probablemente, éste no era el único pescado que adquirían estos individuos, lo que cambiaría bastante las cosas.

En contraste, conviene recordar que algunos pescados de río, como el barbo, valían doce maravedíes, lo mismo que la anguila. Y las especies marítimas, ya fueran el atún o el congrio, podían alcanzar precios superiores: catorce y veinte maravedíes respectivamente, a lo que habría que sumar el acarreo desde la costa hasta la villa correspondiente. La carencia de menciones más específicas a los productos comercializados impide concretar en un sentido u otro, siendo por el momento difícil de determinar su procedencia.

\subsection{Los regatones}

La cuestión de los regatones ha sido poco estudiada hasta el día de hoy, aún teniendo en cuenta la gran importancia que debieron tener de cara al comercio en el interior de las poblaciones medievales. Continuamente los fueros y ordenanzas de las villas remiten una y otra vez a estos personajes, de los que si bien conocemos su actividad comercial, desconocemos su procedencia social.

No es fácil plantear esta cuestión. A pesar de todas las prohibiciones y trabas que se les impusieron, los regatones eran un grupo consolidado. La existencia de una legislación que regulaba su modo de actuación así lo indicaba ${ }^{63}$.

$\mathrm{Su}$ actividad era altamente perniciosa para los intereses del concejo que veía como el control comercial que trataba de imponer era socavado por ellos. Actuaban de manera muy simple: salían a comprar el pescado a los

${ }^{62}$ Millares; ARtiles, Libros de Acuerdos, vol. I, pp. 192-194.

${ }^{63}$ IZQUIERDO, Abastecimiento y alimentación, pp. 167-171. 
términos de la ciudad o incluso lo compraban dentro de la misma ${ }^{64}$. Así evitaban que el producto adquirido fuese controlado por las autoridades y lo introducían en la ciudad si se hallaban dentro, además eludían el paso por la red o por el sitio estipulado para su venta. A continuación, se revendía por un precio superior al permitido por el Ayuntamiento ${ }^{65}$, con lo que el beneficio era grande.

Ante esta violación flagrante de las disposiciones municipales, cabría pensar que los regidores persiguieron con especial inquina a los regatones. Lejos de lo que pudiera creerse no fue así. Parece evidente que en determinadas villas eran contemplados como una parte integrante del comercio local. En Hita o Santorcaz ${ }^{66}$, por ejemplo, se consideraba a la regatería como un oficio más, pudiéndose castigar a sus miembros como al resto de los representantes públicos, estando sometidos como ellos a las mismas leyes, e incluso disponiendo de sus propias tiendas como ocurría en Santorcaz.

Esto nos lleva a preguntarnos una vez más por el grado de integración de los regatones en el comercio local. Los datos que nos ofrece la documentación de la época apuntan a una doble tendencia. Algunas poblaciones, de las que Guadalajara es el mejor ejemplo, poseían una legislación sumamente restrictiva con estos personajes, impidiéndoles a toda costa actuar dentro de su territorio y castigándoles con multas de hacerlo asi ${ }^{67}$. Estamos por tanto ante un concejo duro con los regatones y que les planteaba numerosas dificultades para ejercer su labor.

En segundo lugar tendríamos otras, como Madrid o Toledo, en las que las medidas adoptadas constituirían un ejemplo de intento de integración, a través de normas destinadas a sacarlos de la marginalidad. Se les imponen horarios de venta ${ }^{68}$, control de pesas ${ }^{69}$, e incluso tiendas de la regatería, similares a las que tenían el resto de comerciantes dentro de la legalidad ${ }^{70}$. No

${ }^{64}$ IZQUIERDO, Abastecimiento y alimentación, p. 167.

${ }^{65}$ GAMERo, Ordenanzas antiguas de Toledo, p. 188.

${ }^{66}$ Vid. Luis SÁNCHEZ BELDA, Fueros y Ordenanzas municipales de la Villa de Santorcaz en “AHDE”, 16 (1945), p. 660.

${ }^{67}$ LAYNA, Historia de Guadalajara y sus Mendozas, vol. II, pp. 506 -507.

${ }^{68}$ IZQUIERDO, Abastecimiento y alimentación, p. 186.

${ }^{69}$ Domingo, Documentos del Archivo de la Villa, vol. III, pp. 561 -565.

${ }^{70}$ Además, en 1490 se ordenó que la tienda de la regatería se igualase en los precios con las demás de la villa lo que indica claramente el sentido uniformizador de esta medida. Vid. GómEZ, Libros de Acuerdos, vol. II, pp. 222-223. 
parece sin embargo que el éxito culminase dichos esfuerzos. Aquí entraría en juego una cuestión muy importante. Si el regatón compraba para revender y revendía a un precio desorbitado ${ }^{71}$, es poco probable que se sintiese inclinado a aceptar esa integración que le proponía el concejo. En favor de esta hipótesis jugaría el hecho de que no hemos hallado evidencias de que dispusiesen de un segundo oficio, lo que creemos hablaría bien a las claras del sustancioso beneficio conseguido con esta actividad.

Con todo, se adivina un esfuerzo por parte de los regidores y de los concejos para integrar a los regatones dentro del sistema de comercio legal imperante en las ciudades y villas de la zona. La regatería, por tanto puede ser considerada como un oficio más en el conjunto de las actividades mercantiles, puesto que las iniciativas adoptadas por los municipios más tolerantes se encaminan en esa dirección: control y sujeción a las normas de los regatones, justo como se hace con el resto de vendedores.

\section{6. Los vendedores ilegales}

Los regatones no eran los únicos que usaban de la venta ilegal para enriquecerse. Las fuentes se hacen eco de otras personas cuyas prácticas y modo de actuación se aproximaban muchísimo a la ejercida por estos individuos. Valga como ejemplo lo ocurrido en Sigüenza, donde se referían las andanzas de tenderos, obligados y comunes vendedores a los que se prohibió: "(...) comprar en la cibdad ni fuera de ella en sus terminos provisiones o mercaderías algunas fasta tanto que lleguen a la cibdad e esten en ella un día natural (..." $)^{172}$. Como podemos observar el sistema es prácticamente calcado del que vimos usar a los regatones. Sin embargo estas personas no son calificadas como tales. ¿Qué es lo que les distingue de los regatones? ¿Porqué a unos se les denomina e incluye en un grupo y a otros no?

Acabamos de ver que el sistema empleado es el mismo. Podría diferir a modo de hipótesis el fin: los vendedores lo venden al precio fijado por el concejo, pero adquiriéndolo a un precio inferior. No obstante tal idea, estando

\footnotetext{
${ }^{71}$ GAMERO, Ordenanzas de Toledo, p. 188.

${ }^{72}$ Toribio Minguella y ARNEDO, Historia de la diócesis de Sigüenza y de sus obispos, vol. II, Madrid, 1912, pp. 649 -655.
} 
de por medio los regatones, que lo comprarían a precios más elevados, es absurda.

Podría ser la frecuencia con que efectuaban este tipo de operaciones. A diferencia de los regatones, estas personas sí tienen un segundo oficio, por lo que podría tratarse de una actividad esporádica. Las ordenanzas de Guadalajara dicen que esta gente venía a vender pescado a la villa ${ }^{73}$, dedicándose en un segundo término a esta actividad ilícita, con lo que su intencionalidad sería en principio diferente a la del regatón que busca la mercancía para revenderla. Por tanto es probable que sea la disponibilidad o no de un segundo oficio, lo que diferencie a los regatones de estos individuos, que imitan su modo de actuar y que buscan sus mismos objetivos pero que no son reconocidos por las fuentes como regatones.

El resto de la documentación de otras villas es más ambigua, limitándose a referirse a ellos como "otras personas" o "qualesquier", aunque en ocasiones coinciden con la de Sigüenza señalando la profesión de estas gentes $^{74}$.

\section{CONCLUSIONES}

A lo largo de nuestro artículo hemos tratado de efectuar una primera aproximación a los oficios que de un modo u otro tenían alguna relación con el mundo de la pesca. Dichos oficios los hemos dividido en cuatro bloques. El primero se dedicó a los que capturaban la pesca, englobándose dentro de dicho bloque a los pescadores tanto legales como ilegales. Los primeros destacaban por compaginar, en la mayoría de los casos estudiados, su actividad pesquera con otros oficios que por lo general solían estar relacionados con la pesca, ya como propietarios de posadas o bien vendiendo lo capturado. Además se recoge también la existencia de grupos tales como pescaderas o pescadores también relacionados con la venta de esta mercancía. Respecto a los pescadores ilegales cabe destacar el hecho de que los pescadores pueden llevar a cabo una pesca ilegal, con aparejos prohibidos, si bien queda constatado el hecho de que grupos sociales ajenos a ellos ejercen esta actividad, como los arrendadores de los ríos en Madrid.

\footnotetext{
${ }^{73}$ LaYNA, Historia de Guadalajara y sus Mendozas, vol. II, pp. 506 -507. 4.

${ }^{74}$ Los pescadores venden el pescado en sus casas. Vid. Keniston, Fuero de Guadalajara, p. 
En el segundo bloque se analizó el origen de los arrendadores y aparceros de las propiedades pesqueras. De los arrendadores se dijo que la tipología de los bienes arrendados era muy amplia: molinos, canales, judrias, y que el arrendador debía hacer frente a una serie de compromisos adoptados con el dueño del bien alquilado: mantenerlo en buen estado, hacer las mejores oportunas y todo ello por un tiempo determinado. En todo caso el origen social de los arrendadores es muy diverso figurando incluso entre ellos esclavos y miembros de minorías confesionales. De los aparceros se comentó que sus condiciones eran muy similares a las de los arrendadores: hacían mejoras o reparaciones en el bien y a cambio lo podían explotar por un período de tiempo concreto.

La protección de la pesca fue el tercer bloque abordado. Aquí se analizó la existencia de guardias, tanto en tierras de señorío como en tierras de realengo, con la misión de guardar los términos del municipio o señorío. Además en las tierras de la nobleza se constató la existencia de alcaldes o guardas mayores como los oficiales superiores de los guardas y que éstos debían prendar a los infractores y llevarlos a la justicia, antes siquiera de cobrar nada por su trabajo.

Por último se trató el comercio, planteando la existencia de dos tipos de transacción comercial, la legal, basada en el sistema de obligados y de corredores, y la ilegal, encarnada en los regatones. De los obligados se analizó la escasez de personajes ejerciendo este papel, probablemente a causa de las grandes exigencias de su trabajo, que incluía entre otras cosas, abastecer a la ciudad a un buen precio, con productos de buena calidad y con un margen de beneficios muy pequeño. Además se vio como accedían al cargo por arrendamiento. Asimismo se concretó la existencia de los cortadores como los encargados de cortar el pescado y además de venderlo en los sitios establecidos para ello. De los corredores dijimos que eran nombrados por el concejo y eran los encargados de vender las mercancías que les daban, pero que no abastecían a la ciudad. Como colofón al comercio legal constatamos que el concejo permitía, en determinadas ocasiones, pequeñas operaciones de compra y venta, que podemos relacionar con la incapacidad del obligado para abastecer a la villa.

De los regatones se trató de indicar el grado de asimilación e integración entre los oficios de la villa. Si bien hay algunas poblaciones como Guadalajara, más restrictivas con ellos, otras como Madrid y Toledo les tratan como al resto de comerciantes, sin duda alguna con intención de someterlos e integrarlos a las normas del municipio. Para concluir restaba hablar de los 
vendedores ilegales, similares a los regatones en los métodos empleados, pero con la diferencia de que ellos disponen de un oficio fijo y que su actividad como vendedor ilegal es meramente ocasional. 